\title{
CARACTERIZAÇÃO E COMPORTAMENTO GERMINATIVO DE SEMENTES DE Casearia sylvestris Swartz (SALICACEAE)
}

\author{
MARISTELA IMATOMI ${ }^{1}$, SÔNIA C.J.G. DE A. PEREZZ ${ }^{2,4}$ ALFREDO GUI FERREIRA ${ }^{3,4}$
}

\begin{abstract}
RESUMO - Casearia sylvestris Swartz (Salicaceae), nome popular de guaçatonga ou chá-de-bugre é um arvore amplamente distribuída pelo Brasil e com uso fitoterápico pela população humana que a explora nos ambientes nativos. O objetivo do presente estudo foi fornecer informações sobre o período das fenofases reprodutivas, sua morfologia e germinação de sementes de C. sylvestris, avaliando a existência de variabilidade do comportamento germinativo em lotes de diferentes procedências. Sementes de duas procedências, Itirapina-SP e Ibiporã-PR, com teor de água de 14,5\% e 22,86\%, respectivamente, foram germinadas, na ausência de luz, em temperaturas constantes de 27, 30 e 33 ${ }^{\circ} \mathrm{C}$ ou sob fotoperíodo de $12 \mathrm{~h}$ em temperatura alternada de $20-30{ }^{\circ} \mathrm{C}$, em câmaras BOD. O efeito de reguladores de crescimento foi verificado com soluções de giberelina (10 ou $20 \mathrm{mgL}^{1}$ ) ou cinetina ( 5 ou $10 \mathrm{mgL}^{1}$ ) ou água, sob $27^{\circ} \mathrm{C}$. O teste de tetrazólio mostrou que $32 \%$ das sementes do lote SP e $66 \%$ do PR apresentavam-se viáveis. Os lotes apresentaram o padrão trifásico de embebição de água, diferindo nos tempos de emissão da raiz primária. No teste de temperatura foi determinada a faixa ótima de germinação entre 27 e $30{ }^{\circ} \mathrm{C}$ para os lotes. $\mathrm{O}$ uso de reguladores de crescimento não foi eficaz em melhorar o desempenho das sementes. As plântulas emergidas do lote SP foram mais vigorosas (maior massa), porém de tamanho menor em relação ao lote PR. Após o armazenamento o lote SP apresentou redução na viabilidade e no vigor e o lote PR redução apenas no vigor.
\end{abstract}

Termos para indexação: floração, frutificação, armazenamento.

\section{CHARACTERIZATION AND GERMINATIVE BEHAVIOR OF CASEARIA SYLVESTRIS SWARTZ SEEDS (SALICACEAE)}

\begin{abstract}
Casearia sylvestris Swartz (Salicaceae) is a tree species widely distributed throughout Brazilian vegetation and it is used for medicinal purposes by the human population who exploit natural environment. The purpose of the present study was to provide information about the reproductive phenofases, the morphology and germination of C.sylvestris seeds, and verify the existence of variability in the germination behavior according the source of the seed sample. Seeds from two different sources, Itirapina-SP and Ibiporã-PR, with 14,5\% and 22,86\% water content, respectively, were germinated in the absence of light at constant temperatures of $27^{\circ}, 30^{\circ}$ and $33{ }^{\circ} \mathrm{C}$ and a $12 \mathrm{~h}$ photoperiod in alternating temperatures from $20-30{ }^{\circ} \mathrm{C}$, in BOD chambers. The effect of growth
\end{abstract}

Submetido em 07/02/2008. Aceito para publicação em 08/08/2008.

${ }^{1}$ Universidade Federal de São Carlos (UFSCar), Pós-graduação em Ecologia e Recursos Naturais. Parte da dissertação de mestrado da primeira autora (maristelaimatomi@yahoo.com.br).

${ }^{2}$ Prof. Titular Departamento de Botânica - UFSCar. Bolsista do CNPq. Rodovia Washington Luiz. Km 235. CEP 13565-905, São Carlos, SP (dscp@ufscar.br);

${ }^{3}$ Prof. Titular aposentado da Universidade Federal do Rio Grande do Sul, Bolsista do CNPq.(ferreira@unb.br), Caixa Postal 10015. Porto Alegre, RS, Brasil Cep: 91501-970

${ }^{4}$ Bolsistas de produtividade do CNPq. 
regulators was verified by solutions of gibberellin (GA3)(10 or $\left.20 \mathrm{mgL}^{-1}\right)$ or kinetin (5 or $\left.10 \mathrm{mgL}^{-1}\right)$ or water, under $27{ }^{\circ} \mathrm{C}$ temperature. The tetrazolium test demonstrated that $32 \%$ of the seeds from the SP sample and $66 \%$ of the PR sample were viable. The lots from both sources presented standard three-phase water imbibition, but differed in the emission time of the primary root. The optimal temperature for germination was between $27^{\circ}$ and $30^{\circ} \mathrm{C}$ for both lots. The use of growth regulators was not effective in improving the seed performance. The seedlings from the SP source were more vigorous (larger mass), but they were smaller in relation to the set from the PR source. After storage, the sample from the SP source presented a decrease in their viability and vigor and the ones from the PR source presented decrease only in vigor.

Index terms: flowering, fructification, seed storage

\section{INTRODUÇÃO}

A espécie Casearia sylvestris Swartz Salicaceae (exFlacourtiaceae) é popularmente conhecida como chá-debugre, cafezeiro-do-mato, guaçatonga, sendo classificada como perenifólia, heliófita, ou esciófita e higrófita seletiva. Devido a sua alta capacidade adaptativa esta espécie ocorre em praticamente todo o território brasileiro, apresentando altura de 1-6 m no Sudeste e de até $30 \mathrm{~m}$ no Sul (Lorenzi, 2002) florescendo entre de julho a outubro e com frutificação de outubro a abril (Backes e Irgang, 2002).

C. sylvestris tem sido bastante estudada quanto aos seus princípios farmacológicos, uma vez que as propriedades fitoterápicas de suas folhas e casca foram identificadas como antidiarréicos, anti-reumáticos, diuréticos, antiinflamatórios, antipiréticas (Simões et al., 1986; Lopes, 1997; Alice et al., 1995), antiofídicos (Borges et al., 2001), cicatrizante (Scavone et al., 1979) e, também é utilizada na medicina veterinária para expulsão da placenta de animais após o parto (Simões et al., 1986; Lopes, 1997). Assim, esta espécie nativa é bastante promissora como opção agrícola (Montanari Júnior, 2002) e foi listada como uma das espécies arbóreas prioritárias para conservação e manejo sustentável durante a primeira Reunião Técnica sobre Recursos Genéticos de Plantas Medicinais e Aromáticas (Vieira et al. 2002). Além do uso farmacológico, esta espécie apresenta grande importância para o repovoamento de áreas degradas (Lorenzi, 2002). Como a maioria das espécies nativas com propriedades fitoterápicas, a C. sylvestris não é cultivada, havendo extrativismo em áreas naturais o que promove a degradação da flora nativa e distúrbios em ecossistemas (J.Silva, dados não publicados).

A germinação das sementes é um processo que envolve um conjunto de eventos fisiológicos no embrião, que se inicia com a embebição e culmina com a protrusão da raiz primária dos envoltórios da semente (Castro e Hilhorst, 2004). Para que este processo ocorra são necessárias condições adequadas, tanto ambientais (água, temperatura, luz e oxigênio), quanto intrínsecas (viabilidade, grau de maturidade, dormência e sanidade) à semente (Marcos Filho, 2005).

A disponibilidade de estudos sobre a caracterização da semente e sua germinação, facilitará o cultivo de $C$. sylvestris em grande escala, favorecendo a comercialização para laboratórios farmacêuticos direcionados à produção de medicamentos de origem vegetal, bem como facilitar à uso da espécie em plantios de áreas degradadas.

O objetivo do presente estudo foi o de fornecer informações sobre o período das fenofases reprodutivas, sua morfologia e germinação de sementes de C. sylvestris, e verificar a existência de variabilidade do comportamento germinativo de acordo com a procedência do lote da semente.

\section{MATERIAL E MÉTODOS}

Os processos de floração e frutificação foram acompanhados ao longo de um ano (maio 2005/2006), em matrizes de Casearia sylvestris Swartz, localizadas na área de reserva de cerrado "sensu stricto" da Universidade Federal de São Carlos (UFSCar), campus São Carlos, na região central do Estado de São Paulo (21 $58^{\circ}$ 'S, 4751'W). Verificou-se que nos frutos de guaçatonga nesta área havia intensa predação das sementes e assim houve a necessidade de recoleta de material para realização dos experimentos, a qual foi efetuada em outubro de 2005 no município vizinho de Itirapina (SP), $\left(21^{\circ} 15^{\prime} \mathrm{S}, 47^{\circ} 42^{\prime} \mathrm{W}\right)$. Ao longo deste 
trabalho esta amostra será denominada: lote SP.

Os frutos foram transportados em sacos plásticos até o Laboratório de Ecofisiologia de Sementes da UFSCar onde foram processados para extração das sementes. Devido à presença de arilo ao redor das sementes, foram testados três métodos de extração: a maceração dos frutos em água corrente, com o auxílio de peneira; fermentação dos frutos por período de três dias e, maceração dos frutos em hipoclorito de sódio (3\%). Em seguida, o material ficou exposto ao sol, por curto período, para a retirada da água excedente e depois foi colocado em bancada de laboratório sobre papel de filtro, em temperatura ambiente, para secagem. Após 24 h, o material foi peneirado e as sementes foram selecionadas manualmente (separando-se as com visíveis danos, para posterior análise). Foram então determinados o teores de água das sementes, o número de sementes por quilo, o peso de 1000 sementes e a porcentagem de pureza do lote, procedimentos estes realizados segundo as Regras para Análise de Sementes (Brasil, 1992).

Para comparar sementes de diferente procedência, outro lote foi fornecido pelo Laboratório de Biodiversidade e Restauração de Ecossistemas da Universidade Estadual de Londrina (LABRE/UEL), o qual foi coletado em uma área de Floresta Estacional Semidecidual no município de Ibiporã localizado no Estado do Paraná ( $\left.23^{\circ} 16^{\prime} \mathrm{S}, 51^{\circ} 02^{\prime} \mathrm{W}\right)$, em setembro de 2004. O lote havia sido beneficiado através de maceração em água corrente e permaneceu armazenado durante um ano em câmara fria com temperatura de $15^{\circ} \mathrm{C}$. Ao longo deste trabalho esta amostra será denominada: lote PR.

Foi realizada análise biométrica de oitenta sementes e de oitenta frutos para o lote SP, enquanto, para o lote PR, a análise foi realizada apenas para oitenta sementes, pois estas já foram fornecidas beneficiadas. Com o auxílio de um paquímetro digital foram determinados: a largura, o comprimento e o diâmetro de oitenta sementes e, com uma balança analítica, o massa dos frutos e das sementes. Foi verificado, em trezentos frutos, o número de sementes neles contida e realizada análise de correlação para estabelecer qual à medida que representa melhor a quantidade de sementes no interior do fruto.

Para a determinação da curva de embebição de $C$. sylvestris foram utilizadas quatro repetições de 10 sementes. Estas foram inicialmente pesadas e acondicionadas em placas de Petri de nove $\mathrm{cm}$ de diâmetro, sobre duas folhas de papel de filtro umedecidas com $4,5 \mathrm{~mL}$ de água destilada. As placas foram mantidas em estufa tipo B.O.D. sob temperatura constante de $27^{\circ} \mathrm{C}$. As sementes foram pesadas a cada duas horas e, após o registro de uma tendência de estabilização do peso fresco, as medições foram realizadas a cada $24 \mathrm{~h}$ até a emissão da raiz primária, seguindo o critério botânico para a avaliação de germinação (Labouriau, 1983).

O teste do tetrazólio foi realizado para obtenção de informações sobre a viabilidade das sementes em menor período de tempo. Foram utilizadas cinco repetições de 10 sementes, para cada lote, as quais foram submersas em água destilada durante $6 \mathrm{~h}$ a $30^{\circ} \mathrm{C}$. Em seguida, foram retiradas da água e submersas em solução de tetrazólio $(0,5 \%)$ sob $30^{\circ} \mathrm{C}$ durante $24 \mathrm{~h}$. Após esse período, as sementes foram cortadas longitudinalmente e analisadas em estereomicroscópio (Marcos Filho, 2005).

Os testes descritos abaixo foram todos realizados utilizando-se quatro repetições de 25 sementes, distribuídas em placas de Petri, forradas com duas folhas de papel de filtro e umedecidas com 4,5 mL de água destilada.

Como não foi observada a presença de dormência física de envoltórios e, devido à baixa porcentagem de germinação registrada mesmo sob temperatura ótima, foram utilizados reguladores de crescimento na tentativa de aumentar a porcentagem e a velocidade de germinação destas sementes. Assim, soluções de giberelina (10 ou $20 \mathrm{mgL}^{-1}$ ) ou cinetina (5 ou $10 \mathrm{mgL}^{-1}$ ) ou água (controle), foram utilizadas para embeber as sementes, previamente desinfestadas com hipoclorito de sódio a $3 \%$ por cinco minutos, as quais foram mantidas em estufa tipo BOD sob temperatura constante de $27^{\circ} \mathrm{C}$.

A emergência de plântulas foi realizada em casa de vegetação, com temperatura variando entre 25 e $30{ }^{\circ} \mathrm{C}$ e intensidade de luz de 78,25\% da natural pelo uso de sombrite. As sementes foram semeadas a $2 \mathrm{~cm}$ de profundidade, em bandejas de isopor contendo uma mistura de substrato agrícola com vermiculita na proporção 1:2. Foram consideradas emergidas, as plântulas que apresentavam os cotilédones acima do substrato e, completamente abertos. Quatro meses após a emergência foram medidas com auxílio de paquímetro digital, os comprimentos da parte aérea, do sistema radicular e, o peso fresco verificado com auxílio de uma balança analítica.

As sementes de ambos os lotes foram armazenadas em sacos de papel que foram inseridos em embalagem de vidro e mantidas em geladeira $\left( \pm 5^{\circ} \mathrm{C}\right)$ durante um ano. As sementes do lote PR que estavam armazenadas há um ano quando foram adquiridas, foram imediatamente avaliadas e após dois anos (um ano de armazenamento após a obtenção) foram reavaliadas. Também foi realizado o armazenamento lote SP durante um ano (após a colheita). Depois deste período, 
foi realizada avaliação fisiológica das sementes através da determinação do teor de água e de teste de germinação segundo as Regras para Análise de Sementes (Brasil, 1992).

Foram calculadas a porcentagem, o tempo médio, a velocidade e a freqüência acumulada de germinação conforme Labouriau e Agudo (1987) e Nakagawa (1994). Os dados de germinação foram transformados para $\operatorname{arcsen} \sqrt{G / 100}$ , como recomendado por Zar (1999). A análise estatística utilizada foi baseada em um delineamento experimental inteiramente casualizado, com quatro repetições de 25 sementes para cada tratamento. O conjunto de dados foi submetido ao teste de Lillifors. Para analisar a influência de procedência da semente (lote SP e PR), dos tratamentos (teste de temperatura, influência de reguladores de crescimento e emergência de plântulas) e a interação entre ambos, foi aplicada uma análise de variância (ANOVA fatorial A xB). Como todos os dados não seguiam distribuição normal, foi aplicada uma análise de variância não paramétrica KruskalWallis (Zar, 1999; Santana e Ranal, 2004). Todas as análises foram realizadas utilizando-se o programa estatístico BioEstat 3.0.

\section{RESULTADOS E DISCUSSÃO}

\section{Floração e Frutificação}

Em junho de 2005, a população de guaçatonga do cerrado do "campus" da UFSCar encontrava-se no início do período reprodutivo, apresentando botões florais com cada flor medindo aproximadamente $0,3 \mathrm{~mm}$ de diâmetro (Figura 1a). Após um mês, as flores dobraram o seu diâmetro passando a apresentar 0,6 mm (Figura 1b) e, cresceram gradualmente até o final do mês de agosto (Figura 1c), quando se iniciou o período da antese, e as flores abertas alcançaram diâmetro de $3 \mathrm{~mm}$ (Figura 1d). Em outubro os frutos verdes apresentavam comprimento de $5 \mathrm{~mm}$ e com esta medida passaram a exibir coloração marrom esverdeada para o epicarpo e alaranjada para o mesocarpo (Figura 1e e 1f). Logo a seguir, iniciou-se o período de deiscência dos mesmos, quando a polpa e a semente se desprenderam da casca, que se abriu pela divisão em três valvas (Figura 1f). Esse período é o ideal para a coleta dos frutos (Lorenzi, 2002).

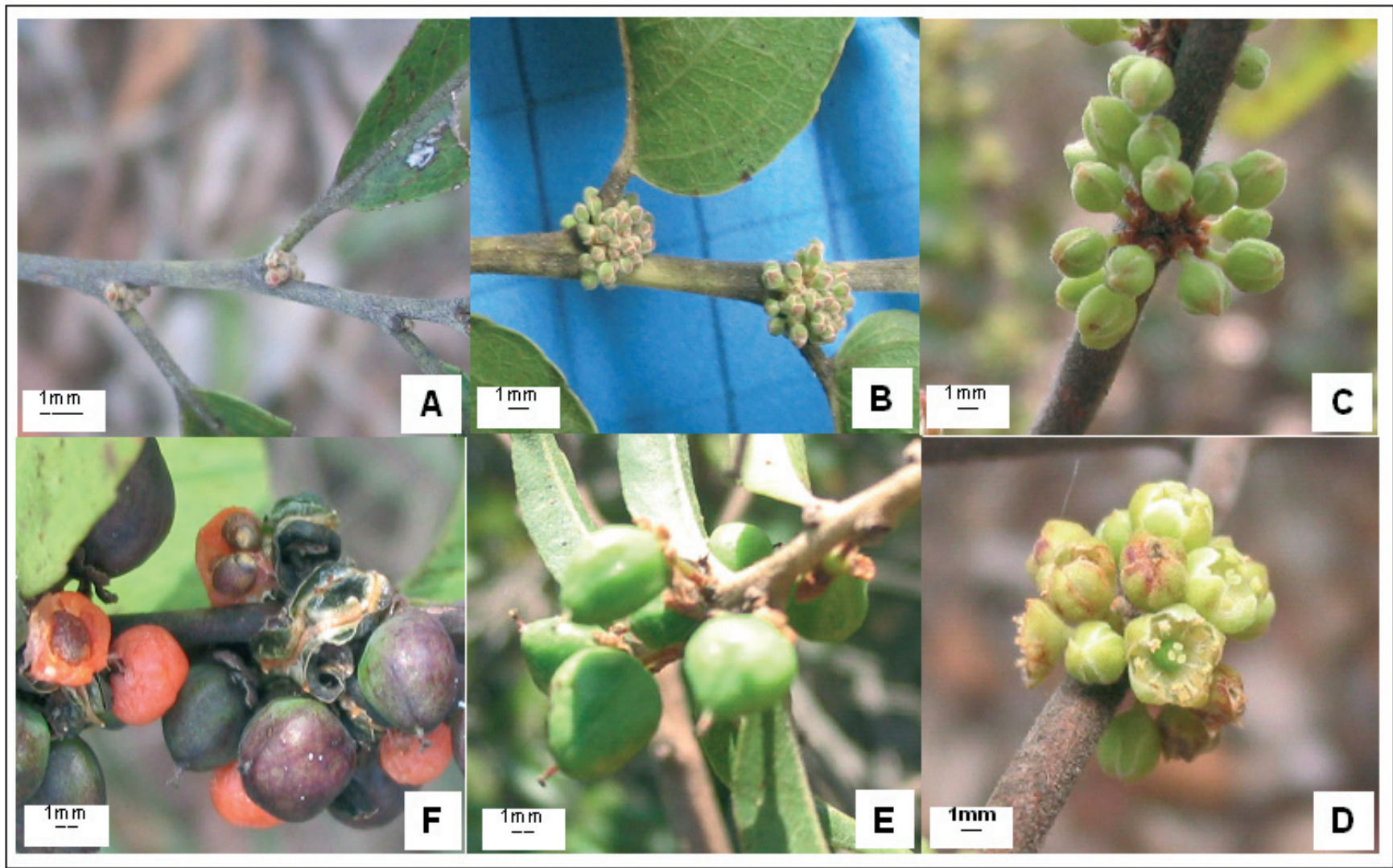

FIGURA 1. A) Botão floral em estádio inicial de desenvolvimento; B e C) Botões florais; D) antese; E) frutos verdes; F) frutos maduros e após a deiscência. 
Os períodos de floração e frutificação diferem na ampla distribuição da C. sylvestris, muitos autores, em diferentes localidades, registraram a ocorrência das fenofases reprodutivas em diferentes meses. Assim, Backes e Irgang (2002) descrevem a floração com início em julho e a frutificação em setembro, para plantas nativas do estado do Rio Grande do Sul, enquanto Silva Júnior (2005) descreve a floração em maio e a frutificação em junho para as plantas do Distrito Federal. Porém, Rizzini (1997) afirma que a floração teve início no mês de outubro no estado de Minas Gerais. Em outros trabalhos também foram descritas a ocorrência do período reprodutivo em diferentes meses para esta espécie (Torres e Yamamoto, 1986; Almeida et al., 1998; Marquete, 2001). Observar-se por meio destas informações que variações no período de ocorrência das fenofases reprodutivas, podem ser devidas a variabilidade genética e de plasticidade fenotípica que permitem às plantas a sobrevivência em variados ambientes (Dirzo e Sarukhán, 1984; Baskin e Baskin, 2001). A presença de plasticidade fenotípica, produção de grande número de sementes e a habilidade de colonizar habitat aberto, aliado a outros fatores, sugerem que a mesma poderia ser uma estrategista-r (McArthur e Wilson, 1967; Kitajima e Fenner, 2000), ou seja, alocam grande parte de sua energia na reprodução em detrimento da manutenção dos indivíduos (Melo et al, 2004).

\section{Extração das sementes}

A maceração dos frutos em água corrente foi o método mais eficaz para a extração das sementes de C. sylvestris, pois foi um método rápido, fácil e que não causou danos ao tegumento, os demais métodos utilizados não foram eficazes, por algum dano causado (dados não apresentados).

O rendimento das sementes de C. sylvestris do lote SP foi obtido com base no peso do fruto fresco, do qual um quilograma rendeu $54 \mathrm{~g}$ de sementes. Dessa quantidade, 42 $\mathrm{g}$ incluíam sementes abortivas ou predadas, restando apenas $12 \mathrm{~g}$ de sementes intactas, o que corresponde a $1,2 \%$ de um quilograma de fruto. No entanto, esta quantia resultou em 6122 sementes. As sementes de guaçatonga do lote SP apresentaram-se intensamente predadas com o embrião danificado. Essa predação foi promovida por insetos fitófagos, sendo duas espécies pertencentes ao gênero Bracon, uma espécie ao gênero Phanerotoma e uma ao Brassus, incluídos na família Braconidae que pertence à ordem Hymenoptera (Nascimento \& Penteado-Dias, comunicação pessoal).

\section{Biometria do fruto e da semente}

Foi calculado que um quilograma de sementes de $C$. sylvestris do lote SP e continham aproximadamente $510 \mathrm{mil}$ sementes, enquanto as do lote PR continham 834 mil e, a diferença entre os dois lotes corresponde a 39\% (Tabela 1). Há dado na literatura de ter quilograma 84 mil sementes por quilograma (Lorenzi, 2002). As diferenças encontradas entre os tamanhos das sementes dos dois lotes de C. sylvestris sugerem diferenças devido localidades de origem dessas sementes, uma vez que o tamanho das sementes pode ser alterado por variabilidade genética e de acordo com a disponibilidade de água, luz, nutrientes, condições intrínsecas à matriz e posição do fruto na planta (Fenner e Thompson, 2005).

Os frutos de C. sylvestris apresentaram grande variação com relação ao número de sementes em seu interior, variando de uma a 12 sementes por fruto, sendo que a maioria dos frutos analisados, continha de uma a três sementes (Tabela 1). O índice de correlação realizado evidenciou que a largura do fruto foi o parâmetro que forneceu melhor informação da quantidade de sementes contidas no interior do fruto (Tabela 2).

TABELA 1. Valores médios, desvio padrão e coeficiente de variação, referentes à análise biométrica da semente (lote SP e PR) e do fruto (lote SP). $\mathbf{N}=\mathbf{8 0}$

\begin{tabular}{lcc}
\hline \multicolumn{1}{c}{ Parâmetros/ Lote } & Lote SP & Lote PR \\
\hline Peso fruto (g) & $0,05 \pm 0,03$ & - \\
Comprimento fruto (mm) & $5,40 \pm 0,87$ & - \\
Largura fruto (mm) & $4,45 \pm 0,87$ & - \\
Altura fruto (mm) & $4,17 \pm 0,92$ & - \\
Número de sementes por fruto & $2,36 \pm 1,68$ & - \\
Peso da semente (g) & $0,002 \pm 0,0007$ & $0,0012 \pm 0,0003$ \\
Comprimento da semente (mm) & 2,45 & 1,68 \\
Largura da semente (mm) & 1,67 & 1,13 \\
Número de sementes por Kg & 510.000 & 834.000 \\
Peso de mil sementes (g) & $1,96 \pm 0,0007$ & $1,23 \pm 0,0003$ \\
\hline
\end{tabular}


TABELA 2. Índice de correlação obtido para os diferentes parâmetros biométricos avaliados.

\begin{tabular}{|c|c|c|c|c|c|c|c|c|}
\hline & \multicolumn{4}{|c|}{ Fruto } & \multicolumn{4}{|c|}{ Semente } \\
\hline & $\mathrm{PF}(\mathrm{g})$ & $\mathrm{C}(\mathrm{mm})$ & $\mathrm{L}(\mathrm{mm})$ & $\mathrm{A}(\mathrm{mm})$ & $\mathrm{N}$ & $\mathrm{C}(\mathrm{mm})$ & $\mathrm{L}(\mathrm{mm})$ & $P F(g)$ \\
\hline \multicolumn{9}{|l|}{ Fruto } \\
\hline $\mathrm{PF}(\mathrm{g})$ & 1,00 & & & & & & & \\
\hline $\mathrm{C}(\mathrm{mm})$ & 0,77 & 1,00 & & & & & & \\
\hline $\mathrm{L}(\mathrm{mm})$ & 0,81 & 0,71 & 1,00 & & & & & \\
\hline $\mathrm{A}(\mathrm{mm})$ & 0,77 & 0,61 & 0,79 & 1,00 & & & & \\
\hline \multicolumn{9}{|l|}{ Semente } \\
\hline $\mathrm{N}$ & 0,67 & 0,61 & $0,69 *$ & 0,58 & 1,00 & & & \\
\hline $\mathrm{C}(\mathrm{mm})$ & $-0,08$ & 0,09 & -0.10 & $-0,13$ & $-0,45$ & 1,00 & & \\
\hline $\mathrm{L}(\mathrm{mm})$ & $-0,27$ & $-0,14$ & -0.26 & $-0,22$ & $-0,44$ & 0,25 & 1,00 & \\
\hline $\mathrm{PF}(\mathrm{g})$ & $-0,02$ & $-0,03$ & $-0,08$ & $-0,06$ & $-0,04$ & 0,00 & 0,31 & 1,00 \\
\hline
\end{tabular}

$\mathrm{PF}=$ massa fresca; $\mathrm{C}=$ comprimento; $\mathrm{L}=$ largura; $\mathrm{A}=$ altura; $\mathrm{N}=$ número de sementes. $\mathrm{N}=80$. *Significativo teste de correlação

O número e o tamanho das sementes podem variar individualmente dentro de uma população e, ainda, dentro de um mesmo indivíduo pode haver variações entre os frutos. Estes dados são importantes, pois estão diretamente relacionados com a germinação e vigor, refletindo-se no estabelecimento da planta a campo e conseqüentemente com a dinâmica da população (Rosa e Ferreira, 2001).

\section{Teste do Tetrazólio}

A concentração de $0,5 \%$ do sal de tetrazólio e a manutenção das sementes de $C$. sylvestris submersas nessa solução durante $24 \mathrm{~h}$ sob $30{ }^{\circ} \mathrm{C}$ foi eficaz na detecção de células vivas no interior da semente. Por intermédio deste teste, verificou-se a existência de número inferior de sementes viáveis do lote SP (32\%) em relação ao lote PR (66\%) (Tabela 3). Comparando este resultado com os obtidos no teste de germinação de sementes $(36 \%)$ e emergência de plântulas (31\%), observa-se que as sementes do lote SP apresentam concordância nos valores obtidos no teste do tetrazólio. Para o lote PR o resultado do teste do tetrazólio não condiz com os dos demais testes, os quais apresentaram porcentagem de germinação (29\%) e emergência de plântulas muito inferior (24\%). Este fato pode ser atribuído a presença de sementes dormentes no lote PR, pois os embriões coraram no tetrazólio, mas, em parte, não germinaram (Tabela 3). A dormência é definida como o bloqueio da germinação de uma semente intacta e viável sob condições ambientais favoráveis. Este bloqueio ocorre de diferentes formas em resposta a diferentes ambientes e esta característica permite que as sementes permaneçam no habitat, germinando no momento oportuno para o estabelecimento da plântula (Hilhorst,1995; Baskin et al., 2004; Fenner e Thompson, 2005; Finch-Savage e Leubner-Metzger, 2006).

TABELA3. Valores médios de germinabilidade, IVG e teor de água de sementes $C$. sylvestris submetidas ao armazenamento em geladeira, por um período de um ano para o lote PR e lote SP, comparados aos valores das sementes não armazenadas.

\begin{tabular}{|c|c|c|c|c|}
\hline & \multicolumn{2}{|c|}{$\begin{array}{c}\text { Não } \\
\text { armazenada }\end{array}$} & \multicolumn{2}{|c|}{ Armazenada } \\
\hline & SP & PR & SP & PR \\
\hline $\begin{array}{l}\text { Teste de } \\
\text { tetrazólio (\%) }\end{array}$ & 29 & 66 & $-*$ & $-*$ \\
\hline Germinabilidade & 28,3 & 29,6 & 6,99 & 32,5 \\
\hline $\begin{array}{l}\text { Velocidade } \\
\text { de germinação } \\
\left(\operatorname{dias}^{-1}\right)\end{array}$ & 0,019 & 0,089 & 0,007 & 0,056 \\
\hline $\begin{array}{l}\text { Teor de } \\
\text { água }(\%)\end{array}$ & $\begin{array}{l}14,5 \\
\pm 3,5\end{array}$ & $\begin{array}{c}22,9 \pm \\
4,5\end{array}$ & $\begin{array}{c}9,9 \pm 0 \\
4\end{array}$ & $\begin{array}{c}7,1 \pm 0 \\
8\end{array}$ \\
\hline
\end{tabular}

* Não efetuado.

\section{Curva de embebição}

As sementes de ambos os lotes apresentaram o padrão trifásico de embebição proposto por Bewley e Black (1994), com um aumento rápido de embebição nos primeiras horas. Para as sementes de C. sylvestris do lote SP a estabilização da curva ocorreu por volta de $188 \mathrm{~h}$ e a protrusão da raiz 
primária em $550 \mathrm{~h}$. As sementes do lote PR apresentaram menor porcentagem de absorção inicial de água, em relação ao lote SP, porém, a estabilização da curva ocorreu por volta de quatro horas após o início do experimento e a protrusão da raiz primária se deu em 167 h (Figura 2) A velocidade de absorção de água pela semente possibilita identificar a presença de dormência tegumentar a partir da construção de uma curva de embebição, utilizando-se os valores de peso fresco das sementes (Castro e Hilhorst, 2004). Neste estudo, não se constatou restrições com origem nos envoltórios. Sementes secas sem dormência física absorvem água e, sob condições ótimas, a embebição inicia-se com maior velocidade, seguida por uma fase de estabilização onde ocorrem os principais eventos metabólicos relacionados à germinação. Posteriormente, a semente volta a absorver água como conseqüência da emissão da raiz primária (Bewley e Black, 1994; Bradford, 1995). A velocidade de absorção das sementes varia de acordo com a espécie, com a disponibilidade hídrica, a temperatura, a composição química dos tecidos de reserva e as condições fisiológicas das sementes (Bewley e Black, 1994). Diferenças em conteúdo da água e embebição variam dentro de uma mesma espécie (Felippe, 1990; Godoy e Felippe, 1992; Garcia e Sharif, 1995; Lemos Filho et al., 1997; Garcia e Diniz, 2003).

A
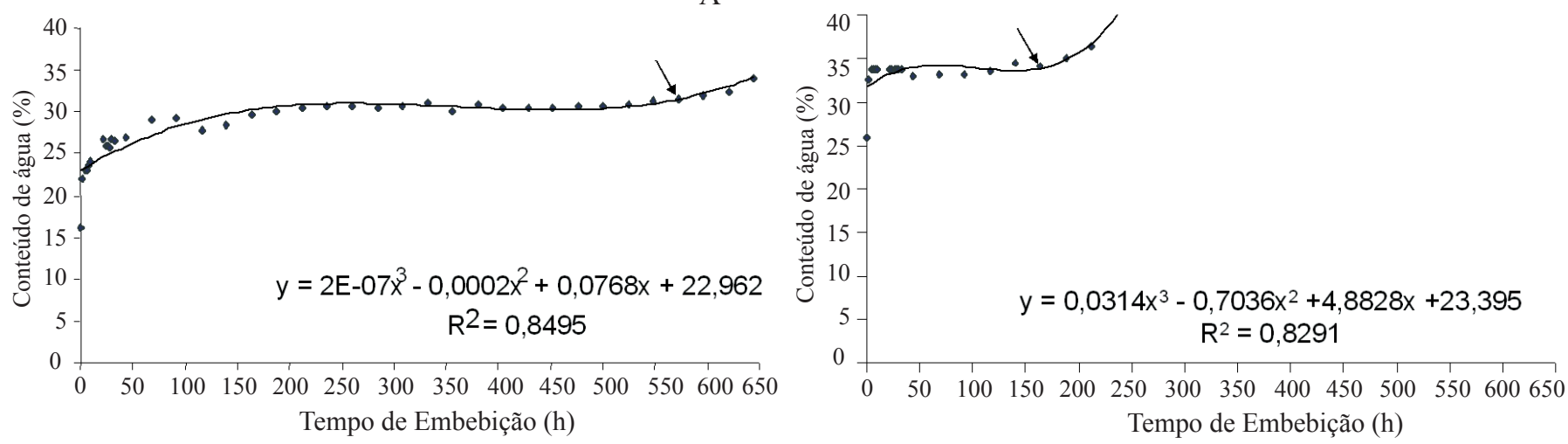

FIGURA 2. Curva de embebição de sementes de $C$. sylvestris mantidas sob temperatura constante de $27^{\circ} \mathrm{C}$ em câmara tipo BOD: A para o lote SP e B para o lote PR. As setas indicam o início da germinação.

\section{Efeito da temperatura}

Verificou-se interação significativa entre os fatores temperatura de incubação e os diferentes lotes de sementes para porcentagem de germinação, porém, a velocidade não apresentou interação entre os fatores. De acordo com os resultados observados para porcentagem de germinação, nota-se que as sementes do lote PR mantiveram constantes os valores de porcentagem de germinação em todas as temperaturas testadas, enquanto as sementes do lote SP apresentaram redução desses valores quando submetidas à temperatura alternada de 20$30{ }^{\circ} \mathrm{C}$ e, supressão da germinação a $33{ }^{\circ} \mathrm{C}$. Nas demais temperaturas testadas, a porcentagem de germinação do lote SP não diferiu dos valores encontrados no lote PR (Figura 3A).

Quanto à velocidade de germinação, observou-se que em todas as temperaturas avaliadas, o lote PR apresentou valor superior ao do lote SP. As sementes do lote PR apresentaram redução significativa dos valores de velocidade quando submetidas à temperatura de $33{ }^{\circ} \mathrm{C}$ e, mantiveram valores constantes de velocidade nas demais temperaturas. Porém, as sementes do lote SP apresentaram redução nos valores de velocidade quando expostas à temperatura alternada de 20-30 ${ }^{\circ} \mathrm{C}$ (Figura 3B).

A temperatura influencia a velocidade e a porcentagem de germinação das sementes, modificando a velocidade das reações químicas que irão acionar o desdobramento, o transporte das reservas e a síntese de novas substâncias para a plântula (Baskin e Baskin, 1988; Bewley e Black, 1994). De maneira geral, temperaturas elevadas provocam diminuição do suprimento de aminoácidos livres, da síntese protéica e das reações anabólicas, podendo desnaturar proteínas e alterar a permeabilidade das membranas (Riley, 1981; Taiz e Zeiger, 2004). Ao contrário, temperaturas mais baixas, provocam atraso na germinação e no crescimento, devido à redução da atividade das enzimas envolvidas na respiração e no metabolismo (Simon et al. 1976, Okusanya 1980, Marcos Filho, 2005). O tempo médio de germinação é 
importante para avaliar a rapidez para o estabelecimento de uma espécie em um determinado ambiente (Ferreira et al., 2001).

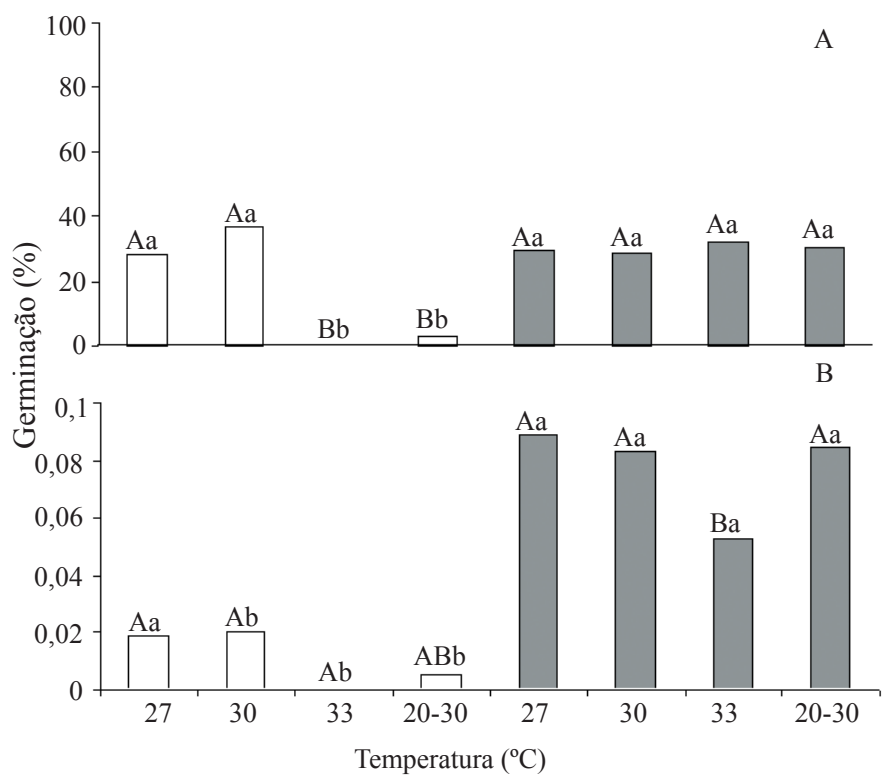

FIGURA 3. Germinação de sementes C. sylvestris submetidas a diferentes temperaturas: A- Valores médios de porcentagem e B-velocidade de germinação dos lotes SP ( $\square$ ) e PR ( $\square$ ), submetidas à diferentes temperaturas em estufa tipo BOD. Letras maiúsculas comparam as temperaturas e as minúsculas comparam os lotes $(\mathrm{P}>0,05)$.

O comportamento de uma espécie quanto à capacidade germinativa varia de acordo com as condições ambientais nas quais a população de origem está inserida. Sementes de C. sylvestris provenientes de populações do Rio Grande do Sul apresentam temperatura de germinação restrita entre 20 e $25^{\circ} \mathrm{C}$ e, tal resposta pode ser um reflexo das condições ambientais experimentadas pela população que se situava no interior da mata, em local sombreado, sem variações drásticas nas temperaturas diárias e sazonais (Rosa e Ferreira, 2001).

\section{Influência de reguladores de crescimento}

Em função da observação de baixa porcentagem de germinação e, do teste de tetrazólio ter indicado sementes viáveis, foram adicionados reguladores de crescimento ao meio germinativo como possíveis substâncias que auxiliassem na superação da dormência. Verificou-se interação significativa entre os reguladores de crescimento e os lotes de diferentes procedências, tanto para porcentagem quanto para velocidade de germinação. Nas sementes do lote SP todos os reguladores de crescimento nas concentrações testadas reduziram a porcentagem de germinação em relação ao grupo controle (Figura 4A). Quanto à velocidade de germinação, nenhum tratamento diferiu do controle (Figura 4B).

Embora as citocininas e as giberelinas possam estimular a quebra da dormência e a germinação de sementes de muitas espécies, nas concentrações usadas não foram eficazes em produzir aumentos na porcentagem e na velocidade de germinação de sementes de C.sylvestris (Figura 4A e B). Pode-se inferir que as concentrações utilizadas não foram adequadas às sementes deste lote PR ou que a dormência não esta regida por estas substancias.

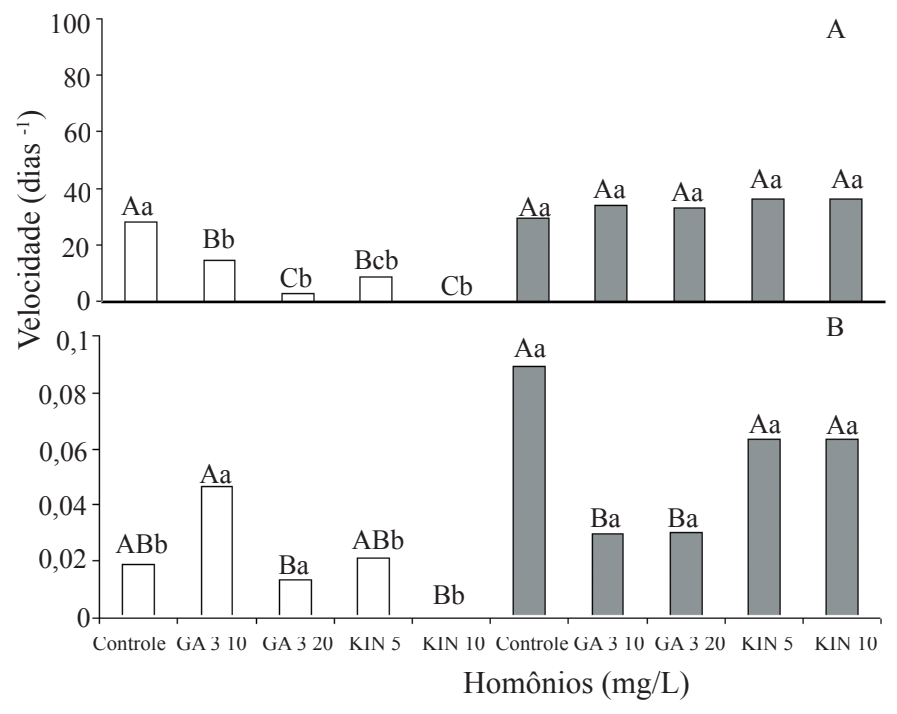

FIGURA 4. Sementes de $C$. sylvestris dos lotes SP ( $\square$ ) e PR $(\square)$ submetidas à diferentes reguladores de crescimento em diferentes concentrações, mantidas sob temperatura constante de 27 ${ }^{\circ} \mathrm{C}$ em estufa tipo BOD: Valores médios de porcentagem $(A)$ e velocidade de germinação (B). Letras maiúsculas comparam os hormônios e as minúsculas comparam os lotes $(\mathbf{P}>0,05)$.

\section{Emergência de plântula}

Os resultados encontrados para a emergência de plântulas provenientes de sementes de C. sylvestris mostraram que os lotes não apresentaram diferença significativa quanto à porcentagem e velocidade de emergência. A emergência teve inicio entre 24 e 28 dias pós-semeadura e, a inclinação da curva e a germinabilidade foram similares para os dois lotes 
(resultados não apresentados). O lote SP apresentou valores semelhantes de comprimento da parte aérea e da raiz e, quando comparados ao lote $\mathrm{PR}$, ambos os valores foram reduzidos. O lote PR apresentou diferença significativa entre o comprimento da parte aérea e da raiz, sendo que a raiz apresentou valor superior em relação à parte aérea (Figura 5A).
$5 \mathrm{~A}$

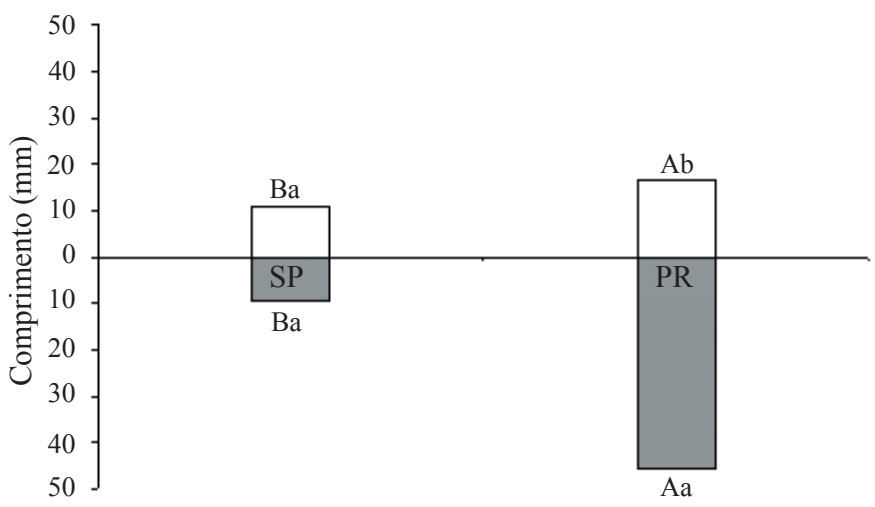

$5 \mathrm{~B}$

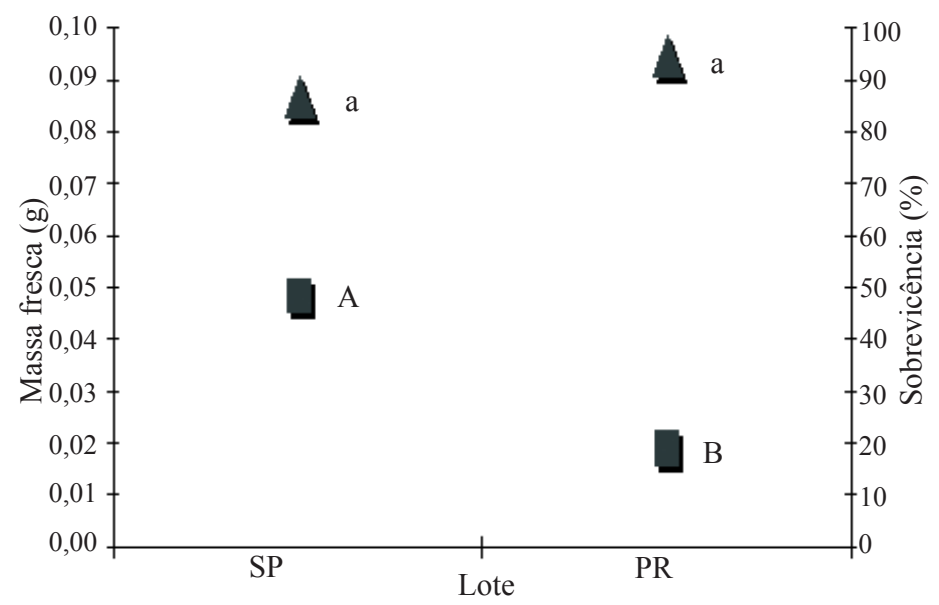

FIGURA 5. Valores médios do: A- comprimento da parte aérea ( $\square$ ) e da raiz ( $\square$ ); B-da massa fresca ( $\square$ )e da sobrevivência de plântulas $(\Delta)$ de $C$. sylvestris dos lotes SP e PR, mantidas em casa de vegetação. Letras maiúsculas comparam os lotes e as minúsculas comparam as partes das plantas dentro de um mesmo lote.

Com relação à massa fresca, o lote SP apresentou peso significativamente superior ao encontrado para o lote PR, embora este último tenha apresentado valores superiores de comprimento da plântula. Foi observado que as plântulas do lote PR eram muito delgadas, por isso apresentaram peso reduzido em relação ao lote SP (Figura 5B). A hipótese de ter ocorrido estiolamento nas plântulas foi descartada devido às condições climáticas de origem de cada lote. $\mathrm{O}$ desenvolvimento inicial das plântulas está intimamente relacionado com a quantidade de reservas disponíveis na semente, portanto, sementes maiores resultam em plântulas mais vigorosas. As plântulas provenientes de sementes menores necessitam de nutrientes advindos do meio, se alongando mais em busca de nutrientes (Baskin e Baskin, 2001).

Outro parâmetro avaliado foi à sobrevivência das plântulas, a qual não apresentou diferença significativa entre os lotes (Figura 5B). Resultados similares foram observados em Lithospermum caroliniense (Weller, 1985). O período de estabelecimento da plântula constitui a fase crítica do ciclo de vida das plantas, pois esta não possui a habilidade, que as sementes apresentam, para suportar as condições adversas e nem apresentam a robustez física adquirida com a idade. Este processo envolve ainda uma série complexa de transições estruturais e metabólicas que dependem de condições ambientais favoráveis. Assim, a mortalidade neste estádio de desenvolvimento é muito elevada (Kitajima e Fenner, 2000; García-Núñes e Azócar, 2004). O polimorfismo das sementes interfere sobre o recrutamento de novos indivíduos dentro da população, uma vez que essa variação altera a porcentagem e a velocidade de germinação. Além disso, a plântula resultante pode variar em tamanho, vigor, habilidade competitiva e no tamanho da planta adulta. Dessa maneira, estudos que avaliam o comportamento germinativo e o desenvolvimento de plântulas, a partir de sementes polimórficas, apresentam grande importância para o entendimento da dinâmica populacional (Baskin e Baskin, 2001).

\section{Teor de água e armazenamento}

O teor de água das sementes de C. sylvestris do lote PR quando recebido para o experimento foi de $25,9 \%$ e para o lote SP, não armazenado, foi de $16,2 \%$. Após, um ano de armazenamento as sementes de ambos os lotes reduziram o seu conteúdo de água em 65,0 e 76,4\%, para SP e PR 
respectivamente (Tabela 3). Quando foram comparados os valores de teor de água com a porcentagem e velocidade de germinação, para o lote SP, constatou-se que houve redução de ambos os parâmetros, o que indica diminuição na viabilidade e no vigor das sementes deste lote. Porém, as sementes do lote PR, que apresentaram maior redução do teor de água durante o armazenamento, reduziram os valores de velocidade, indicando decréscimo do vigor e não da viabilidade. Durante o período de armazenamento, as sementes perderam em média $70 \%$ do conteúdo de água, no entanto este valor corresponde a apenas $0,001 \mathrm{~mL}$ de água por semente. Assim, o conteúdo de água perdido pode ter sido absorvido pela embalagem de papel, uma vez que o volume de água foi pequeno. De acordo com Lorenzi (2002) as sementes de $C$. sylvestris não suportam o armazenamento prolongado sendo sugerido que estas fossem plantadas logo após a retirada do fruto, sendo, portanto, sementes de comportamento recalcitrante (Walters, 2000). Porém, neste estudo constatou-se que alguns lotes desta espécie suportam um período de armazenamento de até dois anos.

\section{CONCLUSÕES}

- Existe variação quanto ao comportamento germinativo e a produção de plântulas de sementes provenientes de duas localidades.

- Lotes de sementes procedentes do Paraná ou de São Paulo germinam melhor entre 27 e $30^{\circ} \mathrm{C}$.

- Pode haver dormência nas sementes, que não é de devida aos envoltórios, sendo que giberelina e citocinina não foram eficientes em superá-la.

- Sementes de guaçatonga podem ser armazenadas, em baixas temperaturas, por até dois anos.

\section{AGRADECIMENTOS}

Agradecemos ao CNPq pelas bolsas concedidas aos autores e ao Biólogo Carlos Casali, pela ajuda no trabalho de campo e em laboratório. A dois assessores anônimos pelas sugestões úteis.

\section{REFERÊNCIAS}

ALICE, C.B.; SIQUEIRA, N.C.S.; MENTZ, L.A.; SILVA, G.A.A.B. DE ; JOSÉ, K.F.D. Plantas medicinais de uso popular: Atlas Farmacognóstico. Canoas: Ed da ULBRA, 1995. 207p.
ALMEIDA, S.P.; PROENÇA, C. E. B.; SANO, S. M.; RIBEIRO, J.F. Cerrado: espécies vegetais úteis. Planaltina: EMBRAPA-CPAC, 1998. 464p.

BASKIN, C. C.; BASKIN, J. M. Germination ecophysiology of herbaceous plant species in a temperate region. American Journal of Botany, v.7, p. 286-305. 1988.

BASKIN, C. C. ; BASKIN, J. M. Causes of within-species variations in seed dormancy and germination characteristics.. In: SEEDS: ecology, biogeography, and evolution of dormancy and germination. New York: Academic Press, 2001. p.181-237.

BASKIN, C. C.; MILBERG, P.; ANDERSSON, L. ; BASKIN, J. M. Germination ecology of seed of the annual weeds Capsella sursa-pastoris and Descurainia sophia originating from high northern latitudes. Weed Research, v.44, p.60-68. 2004.

BACKES, P. ; IRGANG, B. Àrvores do sul: guia de identificação e interesse ecológico. Vila Flores: Impressora Pallotti, 2002. 316p.

BEWLEY, J. D. ; BLACK, M. Seeds: physiology of development and germination. New York: Plenum Press, 1994. 445p.

BORGES MH., SOARES AM., RODRIGUES VM., OLIVEIRA F., FRANSHESCHI AM., RUCAVADO A., GIGLIO JR., HOMSI-BRANDEBURGO MI. Neutralization of proteases from Bothrops snake venoms by the aqueous extract from Casearia sylvestris (Flacourtiaceae). Toxicon, v.39, p.1863-1869. 2001.

BRADFORD, K. J. Water relations in seed germination. In: KIGEL, J. ; GALILI, G. Seed development and germination. New York: Academic Press, 1995. p. 351396.

BRASIL. Ministério da Agricultura e Reforma Agrária. Regras para análise de sementes. Brasília, DF: SND/ DND/CLV, 1992, 365p.

CASTRO, R. D. ; HILHORST, H. W. M. Embebição e reativação do metabolismo. In: FERREIRA, A. G. ; BORGHETTI, F. Germinação: do básico ao aplicado. Porto Alegre: Artmed., 2004. p. 147-162.

DIRZO, R. ; SARUKHÁN, J. Perspectives on plant population ecology. Massachusetts: Sinauer Associates, 1984. 478p.

FELIPPE, G. M. Germinação de Bidens gardneri Baker, uma planta anual dos cerrados. Hoehnea, São Paulo, v.17, p.7-11. 1990.

FENNER M. ; THOMPSON, K. The ecology of seeds. 
Cambridge, U.K. Cambridge: University Press, 2005. 250p.

FERREIRA, A. G.; CASSOL, B.; ROSA, S. G. T.; SILVEIRA, T. S.; STIVAL, A. L. ; SILVA, A. A. Germinação de sementes de Asteraceae nativas no Rio Grande do Sul, Brasil. Acta Botanica Brasilica, v.15, p. 231-242. 2001.

FINCH-SAVAGE, W. E. ; LEUBNER-METZGER, G. Seed dormancy and the control of germination. New Phytologist, v.171, p. 501-523. 2006.

GARCIA, Q. S. ; DINIZ, I. S. S. Comportamento germinativo de três espécies de Vellozia da Serra do Cipó, MG. Acta Botanica Brasílica, v.17, p. 487-494. 2003.

GARCIA, Q. S. ; SHARIF, R. R. Germinação e dormência em aquênios de Acanthospermum hispidum DC, uma espécie invasora. Revista Brasileira de Botânica, v.18, p. 17-25. 1995.

GARCÍA-NÚÑES, C. ; AZÓCAR, A. Regeneration ecology of savanna trees. Ecotropicos, v.17, p. 1-24. 2004.

GODOY, S. M. A. ; FELIPPE, G. M. Qualea cordata: a semente e sua germinação. Revista Brasileira de Botânica, v.15. p. 17-21. 1992.

HILHORST, H. W. M. A critical update on seed dormancy. I. Primary dormancy. Seed Science \& Research, v.5, p.6173. 1995.

KITAJIMA, K. ; FENNER, M. Ecology of seedling regeneration. In: FENNER, M. Seeds: the ecology of regeneration in plant communities. 2.ed. [S.1.]: CABI publishing, 2000. p. 331-359.

LABOURIAU, L. G. ; AGUDO, M. On the physiology of seeds germination in Salvia hispanica L. I. Temperature effects. Anais da Academia Brasileira de Ciências. São Paulo. v.59, p. 37-56. 1987.

LABOURIAU, L.G. A Germinação das sementes. Washington: OEA, 1983. 174p.

LEMOS FILHO, J. P. GUERRA, S. T. M.; LOVATO, M.B. ; SCOTTI, M. R. M. M. L.. Germinação de sementes de Senna macranthera, Senna multifuga e Stryphnodendron polyphyllum, Pesquisa Agropecuária Brasileira, v.32, p. 357-361. 1997.

LOPES, A.M.V. Plantas usadas na medicina popular do Rio Grande do Sul. Santa Maria: Ed. INCOGRAPH, 1997. 49p.

LORENZI, H..Árvores brasileiras: manual de identificação e cultivo de plantas do Brasil. 4.ed. Nova Odessa: Plantarum, 2002. 368p.
MARCOS FILHO, J. Fisiologia de sementes de plantas cultivadas. Piracicaba: FEALQ, 2005. 495p.

MARQUETE, M. Reserva Ecológica do IBGE (Brasília-DF): Flacourtiaceae. Rodriguesia, v.52, n. 80, p. 5-16, 2001.

MCARTHUR, R.; WILSON, E. O. The theory of island biogeography. New Jersey: Princeton University Press, 1967. 203p.

MELO, F.P.L.; AGUIAR NETO, A.V., SIMABUKURO, E.A. ; TABARELLI, M. Recrutamento e estabelecimento de plântulas. In: FERREIRA, A.G. ; BORGHETTI, F. Germinação: do básico ao aplicado. Porto Alegre: Artmed, 2004. p. 237-250.

MONTANARIJÚNIOR, I. Aspectos da produção comercial de plantas medicinais nativas. Centro Pluridisciplinar de Pesquisas Químicas Biológicas e Agrícolas - UNICAMP. Disponível em: <http://www.cpqba.unicamp.br/plmed/ artigos/producao.htm>. Acesso em 2002.

NAKAGAWA, J. Testes de vigor baseados na avaliação das plântulas. In: Vieira, R.D.; Carvalho, N.M. (Ed.). Testes de vigor em sementes. Jaboticabal : FUNEP, 1994. p.59-65.

OKUSANYA, O. T. Germination and growth of Celosia cristata L., and temperature regimes. American Journal of Botany, v.67. p. 854-858. 1980.

RILEY, G. J. P. Effects of high temperature on protein synthesis during germination of Maize (Zea mays L.). Planta, v.151, p. 75-80. 1981.

RIZZINI, C. T. Tratado de fitogeografia do Brasil: aspectos ecológicos, sociológicos e florísticos. 2.ed. Rio de Janeiro: Âmbito Cultural, 1997. 374p.

ROSA, S.G.T. ; FERREIRA, A.G. Germinação de sementes de plantas medicinais Lenhosas. Acta Botanica Brasílica, v.15, p. 147-154. 2001.

SANTANA, D. G.; RANAL, M. A.. Análise da germinação: um enfoque estatístico. Brasília, DF: Editora Universidade de Brasília, 2004. 247 p.

SCAVONE,O.; GRECCHI, R.; PANIZZA, S.; SILVA, R.A.P. DE S. Guaçatonga (Caseraia sylvestris): aspectos botânicos da planta, ensaio fitoquímico e propriedades cicatrizantes de folha. Anais de Farmácia e Química, São Paulo, v.19, p.73-82. 1979.

SILVA JÚNIOR, M. C. DA. 100 árvores do Cerrado: guia de campo. Brasília, DF: Rede de Sementes do Cerrado, 2005. p. 278.

SILVA, E.A.A.da; MELO, L.B. de; DAVIDE, A.C.; DE BODE, N.; ABREU, G.B.; FARIA, J.M.R. ; HILHORST, 
H.W.M. Germination ecophysiology of Annona crassiflora seeds. Annals of Botany, Oxford, v.99, p. 823-830, 2007

SIMÕES, C. M. O.; MENTZ, L. A.; SCHENKEL, E. P.; IRGANG, B. E. Plantas da medicina popular no Rio Grande do Sul. Porto Alegre: Ed. Universidade/UFRGS, 1986. 173p.

SIMON, E. W.; MINCHIN, A.; MCMENAMIN, M. M. ; SMITH, J. M. The low temperature limit for seed germination. New Phytologist, v.77, p. 301-311. 1976.

TAIZ, L; ZEIGER, E. Fisiologia vegetal. Porto Alegre: Ed. Artmed, 2004. 719p.

TORRES, R.B. ; YAMAMOTO, K. Taxonomia das espécies de Casearia Jacq. (Flacourtiaceae) do estado de São Paulo. Revista Brasileira de Botânica, v. 9, p. 239-258. 1986.
VIEIRA, R.E., SILVA, S.R., ALVES, R.B.N., SILVA, D.B., WETZEL, M.M.V.S., DIAS, T.A.B., UDRY, M.C. ; MARTINS, R.C. Estratégias para conservação e manejo de recursos genéticos de plantas medicinais e aromáticas: resultados da primeira reunião técnica. Brasília, DF: Embrapa Recursos Genéticos e Biotecnologia: Ibama: CNPq, 2002. 184p.

WALTERS, C. Levels of recalcitrance in seeds. Revista Brasileira de Fisiologia Vegetal, v.12, p. 7-21. (Número especial). 2000.

WELLER, S. G. Establishment of Lithospermum caroliniense on sanddunes: the role of mass. Ecology, Washington, v.66, p. 1893-1901, 1985.

ZAR, J. H. Biostatistical analysis. New Jersey: PrenticeHall, 1999. 663p. 